\title{
Batik Classification with Artificial Neural Network Based on Texture-Shape Feature of Main Ornament
}

\author{
Anita Ahmad Kasim \\ Department of Computer Science and Electronics, Faculty of Mathematics and Natural Sciences, \\ Universitas Gadjah Mada,Yogyakarta, Indonesia \\ Department of Information Technology, Faculty of Engineering, Universitas Tadulako, Indonesia \\ E-mail: nita.kasim@gmail.com \\ Retantyo Wardoyo and Agus Harjoko \\ Department of Computer Science and Electronics, Faculty of Mathematics and Natural Sciences, \\ Universitas Gadjah Mada,Yogyakarta, Indonesia \\ E-mail: rw@ugm.ac.id, aharjoko@ugm.ac.id
}

\begin{abstract}
Batik is a textile with motifs of Indonesian culture which has been recognized by UNESCO as world cultural heritage. Batik has many motifs which are classified in various classes of batik. This study aims to combine the features of texture and the feature of shapes' ornament in batik to classify images using artificial neural networks. The value of texture features of images in batik is extracted using a gray level co-occurrence matrices (GLCM) which include Angular Second Moment (ASM) / energy), contrast, correlation, and inverse different moment (IDM). The value of shape features is extracted using a binary morphological operation which includes compactness, eccentricity, rectangularity and solidity. At this phase of the training and testing, we compare the value of a classification accuracy of neural networks in each class in batik with their texture features, their shape, and the combination of texture and shape features. From the three features used in the classification of batik image with artificial neural networks, it was obtained that shape feature has the lowest accuracy rate of $80.95 \%$ and the combination of texture and shape features produces a greater value of accuracy by $90.48 \%$. The results obtained in this study indicate that there is an increase in accuracy of batik image classification using the artificial neural network with the combination of texture and shape features in batik image.
\end{abstract}

Index Terms-Batik, Artificial Neural Network, TextureShape Feature.

\section{INTRODUCTION}

Batik is a motifs in textile with a high artistic value, spread across Asia, especially in Central Java Indonesia [1]. The uniqueness of batik fabric comes from the production process called "mbatik". The process of "mbatik" produces patterns that are diverse and high in economic values. Batik designs are inspired by nature or mythology and therefore resulting typical geometrical patterns, various motifs of batik with different names [2]. Thus it makes it difficult in classifying any pattern.

The purpose of image classification in batik is to divide batik image based on the class of each pattern thus can easily be recognized by its features. Batik has a structure model consisting of primary and additional ornaments. Each main ornament in batik has philosophical meaning, for example, Grompol ornament, worn in a wedding ceremony. Gro mpol means to gather or to unite, the hope of collecting everything was excellent as fortune, happiness, offspring, living in harmony and so on [3]. Additional ornamentation is smaller and simple and does not have a philosophical meaning in the composition of batik patterns. In one batik pattern may comprise several other ornamentations.

Batik's textures are diverse. For instance, there are textures with patterns of the edges of bold lines which have a high contrast value or the edges of fuzzy lines which have low contrast values. Regarding the size of the edges of the lines, there are thick and thin. Meanwhile, there is a large, medium and small size of the main batik ornaments [4].

The various number of batik pattern causes difficulties in identifying the patterns in Indonesia. For that, we need a method that can classify each batik pattern based on its main ornament pattern. In this paper, we proposed a classification model of batik image by using neural networks based on texture features and shape features of the main ornaments.

This paper will discuss batik and its classifications in the first part, while the second part presents research ever conducted on batik. The third section discusses the research methods used and finally, the fourth and fifth sections discuss the research's results, discussion, and conclusions. 


\section{RELATED WORK}

Several studies have been conducted for proper classification of batik image [1][5][6][7]. One research on batik was performing classification by color, contrast, and motifs which were the work by Moertini and Sitohang [8]. They used the HSV color model for classifying batik based on wavelet method to extract the color of batik texture feature. The results obtained showed a clustering algorith $\mathrm{m}$ with the colors and textures looking good. The batik texture features can be achieved by the method of co-occurrence matrices of sub-band images. This method can be used to classify batik image which was randomly obtained from the internet. This approach combines the methods of gray-level co-occurrence matrices (GLCM) and discrete wavelet transform (DWT). First of all, the image is composed with DWT to become sub-band image. Then, the texture features of sub-band image are extracted with GLCM. The values of the extracted results become the input to the probabilistic neural networks (PNN). The results are good enough to classify the image of batik. The maximum accuracy that can be achieved is $72 \%$ [9].

Nugrowati, et al[10] proposed an image classification method for a retrieval system of batik image. This method combined the two features; batiks' colors and shapes. They used the 3D-Vector Quantization to extract the color feature. This method is capable of displaying color distribution variously and reducing the complexity of the image color. In addition to color, they used the $\mathrm{Hu}$ moment method to extract the shape feature of batik. The result of the shape feature extraction consisted of orthogonal invariant moments that can be used to scale, position and rotation. Another method used to classify batik is HMTSeg[11]. HMTSeg is used by dividing the batik image into multiple regions based on similarity of features including grayscale levels, texture, color, and motion. The accuracy obtained is by $80 \%$, able to recognize batik image based on texture features. In addition to the use of texture features, batik image can also be classified by combining the features of texture and color statistics [12]. The texture features are extracted from the gray-level co-occurrence matrices (GLCM) consisting of contrast, correlation, energy, and homogeneity. The color feature is extracted with statistical color RGB channel which consists of the mean, skewness, and kurtosis[13]. The result obtained is very well with a value of $90.6 \%$ precision, recall of $94 \%$ and the overall accuracy of $94 \%$.

Additionally, R.Azhar, et al [14][15] used a combination of Bag of Features (BOF) using Scale Invariant Feature Transform (SIFT) and Support Vector Machine (SVM) to classify the batik image. This experiment produced a classification accuracy of $97.67 \%$ for regular batik image, $95.47 \%$ for the rotated image and $79 \%$ for the scaled image. Image data in a class are derived from the image of the textile which is divided into six sub-images. Research Methods

Our method consists of four phases: acquisition, preprocess phase, the phase of features extraction and the image classification phase. The acquisition phase is the process of making batik image using the camera. The preprocessing step is done to process images that have been acquired before being treated earlier to obtain the values of texture and shape features. At this phase of preprocessing, we resize batik image to 256 x 256 pixels and convert it into a grayscale image.

There are two processes at the phase of features extraction; texture feature extraction and shape feature extraction. The values obtained in the features extraction step will be processed at the classification phase by dividing the value of the features data into two parts; the training data and the testing data. The process phase in this study is shown in Fig.1.

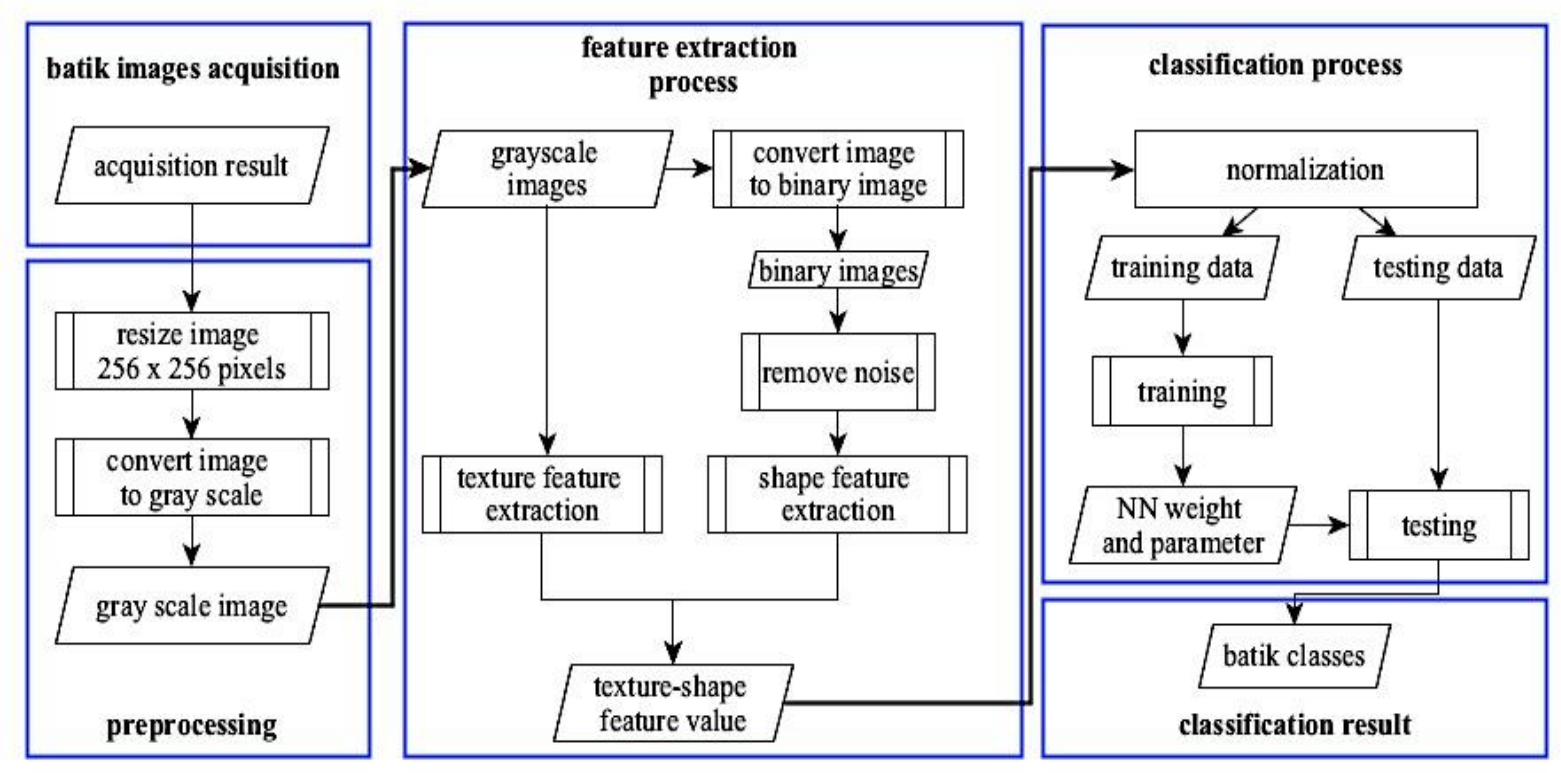

Fig.1. Research Method Diagram 


\section{A. Acquisition and Pre-process of batik images}

The image acquisition process using the camera and focusing on the main ornaments contained in batik fabric. The capturing of the batik image is made by placing the camera in front of batik fabric with a distance that adjusts the size of each main ornament of batik image to be photographed. Furthermore, the size of the image is converted into $256 \times 256$ pixels. The number of batik image to be processed is 140 images from 7 different clas ses which are, ceplok (C), grompol (Gr), gurda $(\mathrm{G})$, kawung $(\mathrm{K})$, mega mendung $(\mathrm{mm})$, parang $(\mathrm{P})$ and sido asih (SA). Then, data are divided into 98 images $(70 \%$ of 140 images) as training data and 42 images (30\% of 140 images) as the testing data. Each class consists of 20 motifs of batik image.

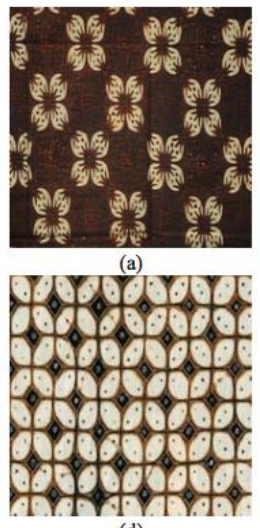

(d)
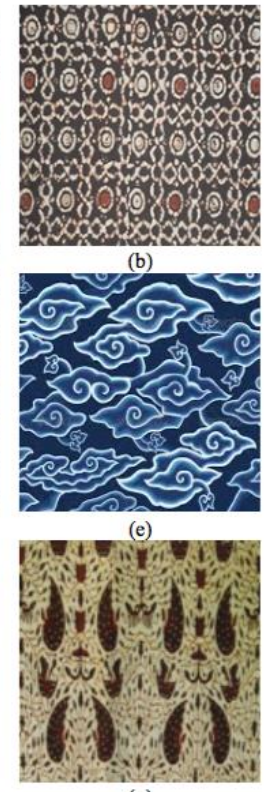

(g)

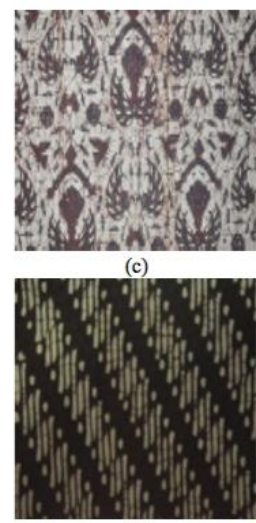

(f)
Fig.2. Batik's motif (a) ceplok (b) grompol (c) gurda (d) kawung (e)mega mendung (f)parang (g) sido asih

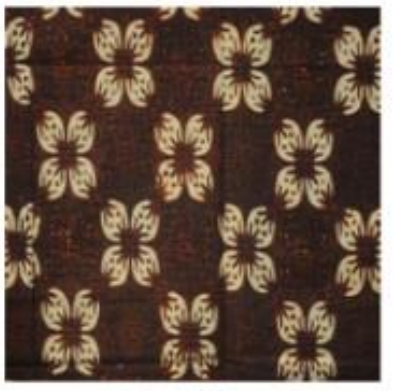

(a)

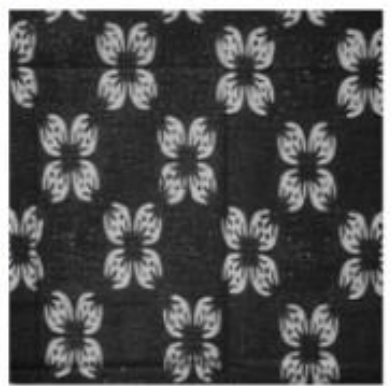

(b)
Fig.3. (a) RGB image (b) Gray scale image

These motifs of batik image acquired in this study are shown in Fig.2. Furthermore, the transformation of the image to grayscale is conducted. The grayscale transformation aims to change the level of gray in the image uniformly grayish or to modify the level of gray by using the mapping function [16]. The grayscale transformation will further facilitate the computation in obtaining values of the feature of batik texture. The result of the transformation of batik image to gray scale is shown in Fig.3.

\section{B. Texture Feature Extraction}

In the feature extraction phase, we process the image resulted in the pre-processing phase into two, with the texture image and the image of batik with main shapes of ornament in batik. The values of texture feature were obtained by using co-occurrence matrices on gray level co-occurrence matrices (GLCM). GLCM is one method to obtain a texture feature by calculating the probability of adjacency relationship between two pixels at a certain distance and angular orientation [17][18]. Texture feature extraction process is shown in Fig.4.

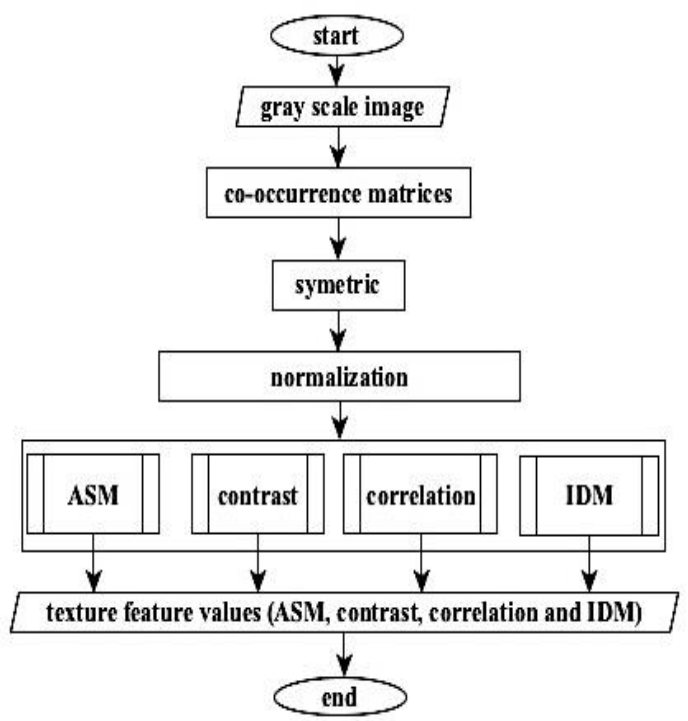

Fig.4. Batik's texture feature extraction method

Four features that we have chosen to be extracted in this study are based on texture features that have been proposed by Haralick [19] Angular Second Moment (ASM) consisting of contrast, correlation and Inverse different Moment (IDM).

The values of texture features are obtained by equation equation (1), (2), (3) and (4) is the number of times the pixels with i gray level happened alongside a $\mathrm{j}$ gray level and $n$ is the number of pixels' pairings. $P(i, j)$ is the distribution of joint probabilities of a pair of pixels with $i$ gray level and $\mathrm{j}$ gray level which can be calculated by dividing $G(i, j)$ with $n$ [19].

\section{Angular second moment (ASM)}

Angular second moment (ASM), also known as the uniformity or energy. ASM is a measure of the homogeneity of an image. ASM value will be high when an image has a uniform texture or when all the pixels look almost the same. ASM values can be obtained by calculating (1) as follows:

$$
A S M=\sum_{i=0}^{G-1} \sum_{j=0}^{G-1}\{P(i, j)\}^{2}
$$




\section{Contrast}

Size contrast or local intensity variations will contribute to $P(i, j)$ on the diagonal, namely, $i=j$. The contrast of a pixel and its neighbors can be calculated by (2) as follows:

$$
\text { Contrast }=\sum_{n=0}^{G-1} n^{2}\left\{\sum_{i=1}^{G} \sum_{j=1}^{G} P(i, j)\right\},|i-j|=n
$$

\section{Correlation}

Correlation (correlation) is the size of the gray level inter-pixel linear dependent on the relative position of each pixel. Correlation can be calculated by (3) as follows:

$$
\text { Correlation }=\sum_{i=0}^{G-1} \sum_{j=0}^{G-1} \frac{\{i \times j\} \times P\{i, j\}-\left\{\mu_{x}-\mu_{y}\right\}}{\sigma_{x} \times \sigma_{y}}
$$

Where $\mu_{x}, \mu_{y} \sigma_{x}$ and $\sigma_{y}$ is mean and $P_{x}$ and $P_{y}$ is standard deviation

\section{Invers different moment (IDM)}

IDM is a local homogeneity. Its value will be high when the local gray scale is uniform, and the inverse GLCM is also great. IDM is very much influenced by the homogeneity of the image, due to a weight factor. IDM will get a little contribution from homogeneity area $(i=j)$. The result of the value of the IDM higher homogeneity of the image is for a relatively compared to the inhomogeneity image. IDM values can be obtained by calculating (4).

$$
I D M=\sum_{i=0}^{G-1} \sum_{j=0}^{G-1} \frac{1}{1+(i-j)^{2}} P(i, j)
$$

\section{Shape Feature Extraction}

The main ornament batik image obtained by transform batik image into a binary image using Otsu method and to reduce noise in the shape of ornaments use binary morphology method [16].

The purpose of Otsu method is to divide the gray level image histogram into two distinct areas automatically without requiring the user to enter threshold value. The approach taken by the Otsu method is to perform a discriminant analysis the variables that can distinguish between two or more groups.

A discriminant analysis will maximize these variables in order to divide the images into an object (foreground) and background [20]. The result of batik image binarization by Otsu method and a binary morphological operation to remove noise is shown in Fig.5.

We calculate some parameters of shapes to obtain the values of shape feature in batik ornament i.e. area, perimeter, major axis length, minor axis length, and convex hull. The area is the number of pixels in the area described by the shape of batik ornament (foreground) denoted with (A). The perimeter is the number of pixels at the edge of the shape of batik ornament denoted with (P).

Major axis length is the maximum length of the shapes of batik ornament in a bounding box denoted with (L). Minor axis length is the minimum length of the shapes of batik ornament in a bounding box denoted with $\mathrm{W}$. Convex-hull is an outside line that surrounds all the points of contour on batik ornaments denoted with $\mathrm{CH}$. Based on the parameters of the area, perimeter, major axis length, minor axis length and convex hull, it is obtained the following ornament shape features in batik. Steps to get the value of shape feature shown in Fig.6.

Based on the parameters area, perimeter, major axis length, minor axis length, and the convex hull is obtained the batik shape feature as follows[16]:

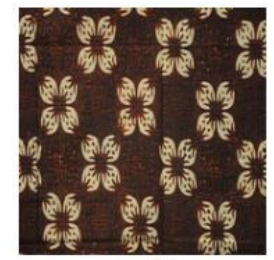

(a)

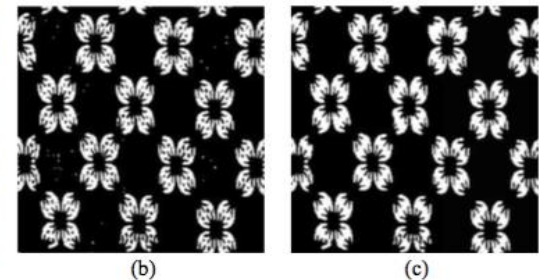

(b) (c)
Fig.5. (a) RGB image (b) binary with Otsu method (c) binary image with morphological binary

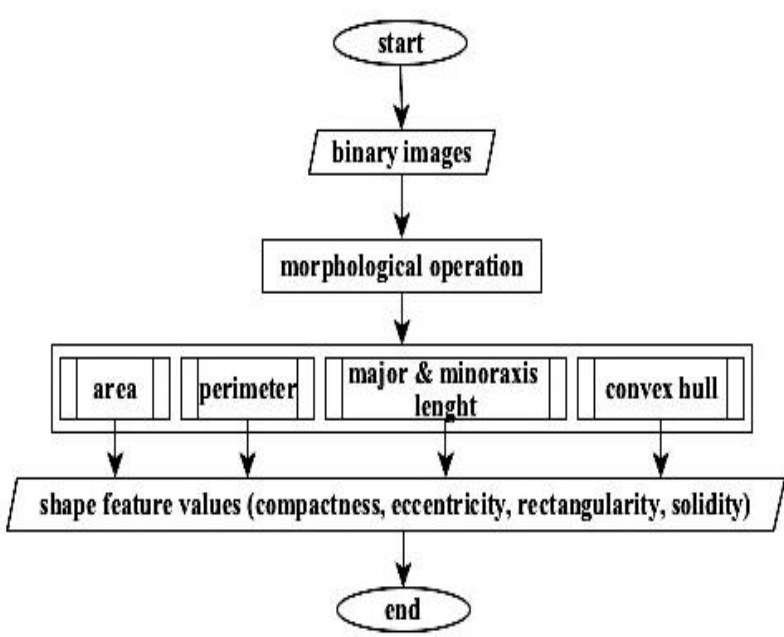

Fig.6. Batik's shape feature extraction method

\section{Compactness}

Compactness is the ratio of the perimeter and the area of the shapes of batik ornaments. We use (5) to calculate the value of compactness.

$$
\text { compactness }=C=\frac{P^{2}}{A^{2}}
$$

\section{Eccentricity}

Eccentricity is The ratio of major axis length to the 
minor axis length. This can be calculated with the basics of the method of an axis or the method of minimum bounding. We use (6) to calculate the value of Eccentricity

$$
\text { eccentricity }=E=\frac{L}{W}
$$

\section{Rectangularity}

Rectangularity represents how rectangular a shape (how much it fills minimum bounding rectangle). Rectangularity can be seen as the ratio between the area forms batik ornament with eccentricity values formulated in (7)

$$
\text { rectangularity }=R=\frac{A}{E}
$$

\section{Solidity}

Solidity represent the extent to which the shape is convex or concave and it is defined by (8).

$$
\text { solidity }=S=\frac{A}{C H}
$$

\section{Classification Process of Batik Images}

There are several training algorithms for classification process. The algorithm uses the gradient performance function to determine optimal weights in the neural network. These methods called back propagation, which involves performing computational backwards through the network[21]

We proposed a classification process of batik image based on texture-shape features using artificial neural networks with backpropagation learning methods. Backpropagation is a gradient reduction method to minimize the error squared algorith $m$ output using weight adjustment patterns to achieve minimum error value [22].

The function of training used in this model is the Levenberg-Marquardt optimization with the training function adaptation of Gradient descent function with backpropagation momentum. The parameters in the neural networks consist of epoch $=1000$, minimal perform gradient $=0.0000001$, the target goal $=0.1$, the learning rate $=0.01$ and the constant momentum $=0.9$.

The selection of activation function increases the complexities of the subsequent steps in neural network model design. It is makes the classification task difficult. Instead, the choice of the appropriate activation function can provide ease of subsequent steps in the neural network and produce a better performance. [23].

Each layer of artificial neural networks has an activation function of training or the transfer function that serves to bring the input to the desired output. The transfer function will determine the amount of the weight in each layer. We tested the combination of the activation function of network training to obtain a goof transfer function for training the artificial neural networks of batik classification. The activation function of training tested in this study consisted of:

\section{Logsig}

Logsig is the activation function which brings input to output with calculations Log-Sigmoid. Output value between 0 and 1 . The sigmoid activation functions are shown in Fig.7 with the function (9).

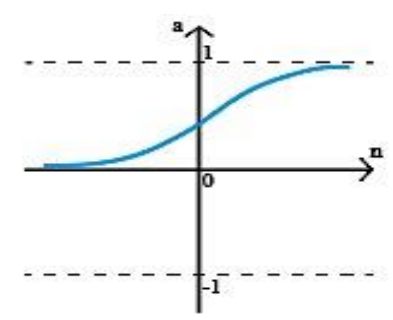

Fig.7. log-sigmoid activation function

$$
\log \operatorname{sig}(n)=\frac{1}{1+(\exp (-n))}
$$

\section{Tansig}

Tansig is the activation function of the training will take inputs to outputs using the formula hyperbolic tangent sigmoid. The maximum value of the output of this function is -1 and the minimum output is -1 . Tansig activation function shown in Fig.9 with the function (10).

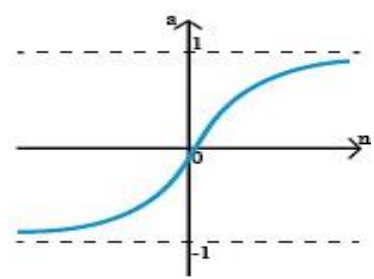

Fig.8. tan-sigmoid activation function

$$
\operatorname{tansig}(n)=\frac{2}{1+(\exp (-2 n))}
$$

\section{Purelin}

Purelin is the input to output transfer function is linear. Purelin activation function shown in Fig.9 with the function (11)

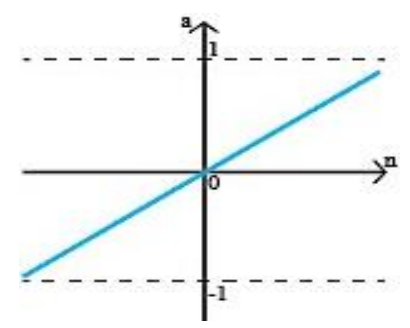

Fig.9. purelin activation function 


$$
\operatorname{purelin}(a)=n
$$

\section{RESULT AND DISCUSSION}

We propose Artificial neural network that consists of one input layer with 20 neurons (the value of textureshape features), one hidden layer consisting of 10 neurons and one layer of output consisting of 3 neurons for defining seven classes of batik images: Ceplok, Grompol, Gurda, Kawung, Mega Mendung, Parang, and Sidoasih. The neural network architecture with texture-shape features is shown in Fig.10. For the weight and bias activation function, we used a combination of logsig activation function on Layer 1 and the tansig activation function on layer 2. To determine the activation function used in this study, we tested the two combinations of activation functions. The plot regression test result with logsig activation function is shown in Fig.11 and the plot regression test result with tansig is activation function shown in Fig.12.

Fig.11 and Fig.12 represent the result of the trial of activation function to the training data, the validating data and the testing data. The dotted lines indicate the exact result of output $=$ target. The solid line shows the best fit linear regression between outputs and targets. The $\mathrm{R}$ value shows the relationship between outputs and targets. If $\mathrm{R}=1$, it means that there is a linear relation between outputs and targets. If $\mathrm{R}$ is approaching zero, then there is no linear relationship between outputs and targets.

The result of the combinations activation function test can be seen in Table 1.
Based on Table 1, the combination of the logsig activation function on Layer 1 and the purelin activation function on Layer 2 has a higher linearity of 0.84 (training), 0.86 (validation), 0.79 (testing) and as a whole amounted to 0.86 . Thus, in this study, we used the combination of logsig and purelin to classify the batik image. The training process shows the classification accuracy of each class image of batik and batik images classification accuracy overall. Furthermore, training results tested using test data that has been provided.

To obtain the value of accuracy is done by counting the number of successful data classified or that have a match with the target neural network divided by the total number of data.

The results of the accuracy of each class and overall accuracy displayed in multiclass confusion matrices. Multiclass confusion matrices that we use consists of seven classes according to the number of batik classes used in these research is Ceplok, Grompol, Gurda, Kawung, Mega mendung, parang and Sido Asih.

Through the matrices, it can be shown the number of batik image data classifications that are classified correctly and misclassification for each class.

Table 1. The combination of the activation function

\begin{tabular}{|c|c|c|c|c|c|}
\hline $\begin{array}{c}\text { The combination } \\
\text { of the activation } \\
\text { function }\end{array}$ & \multicolumn{4}{|c|}{$\mathbf{R}=$ input and output linearity } \\
relationship
\end{tabular}

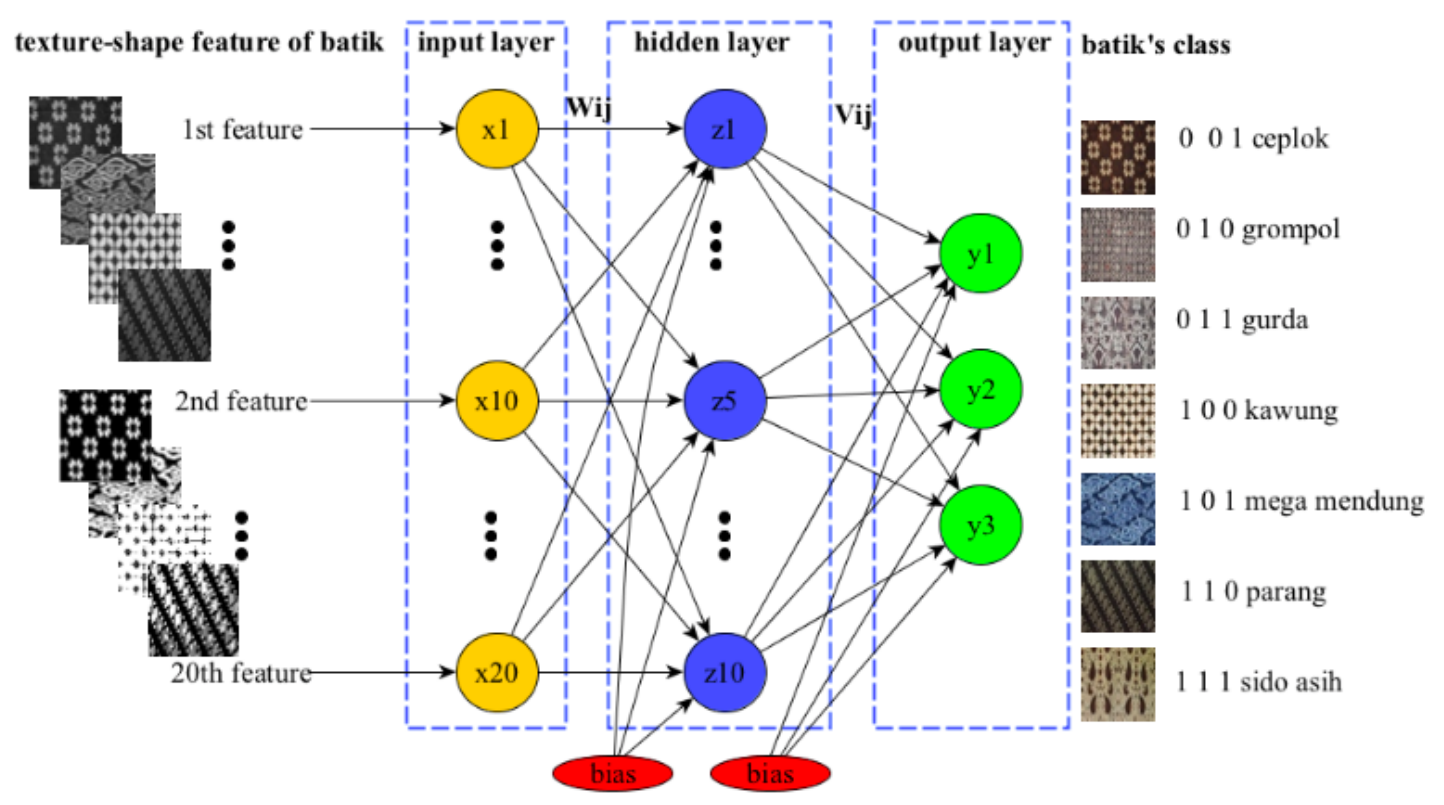

Fig. 10. Neural Network Architecture for texture-shape main ornament of Batik Classification 

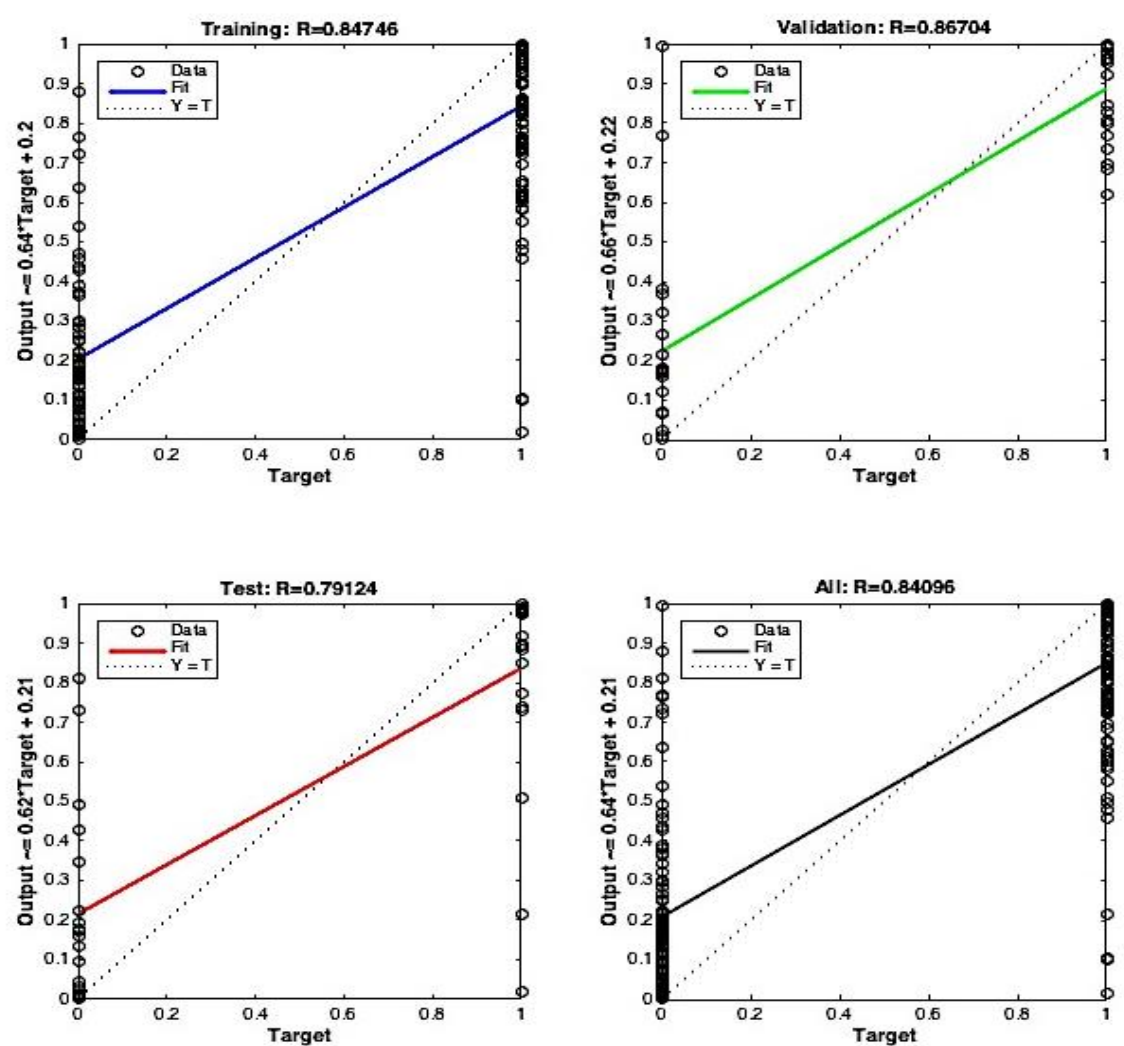

Fig.11. Regression plot trial activation function logsig-purelin (a) Training (b) Validation (c) Testing (d) All
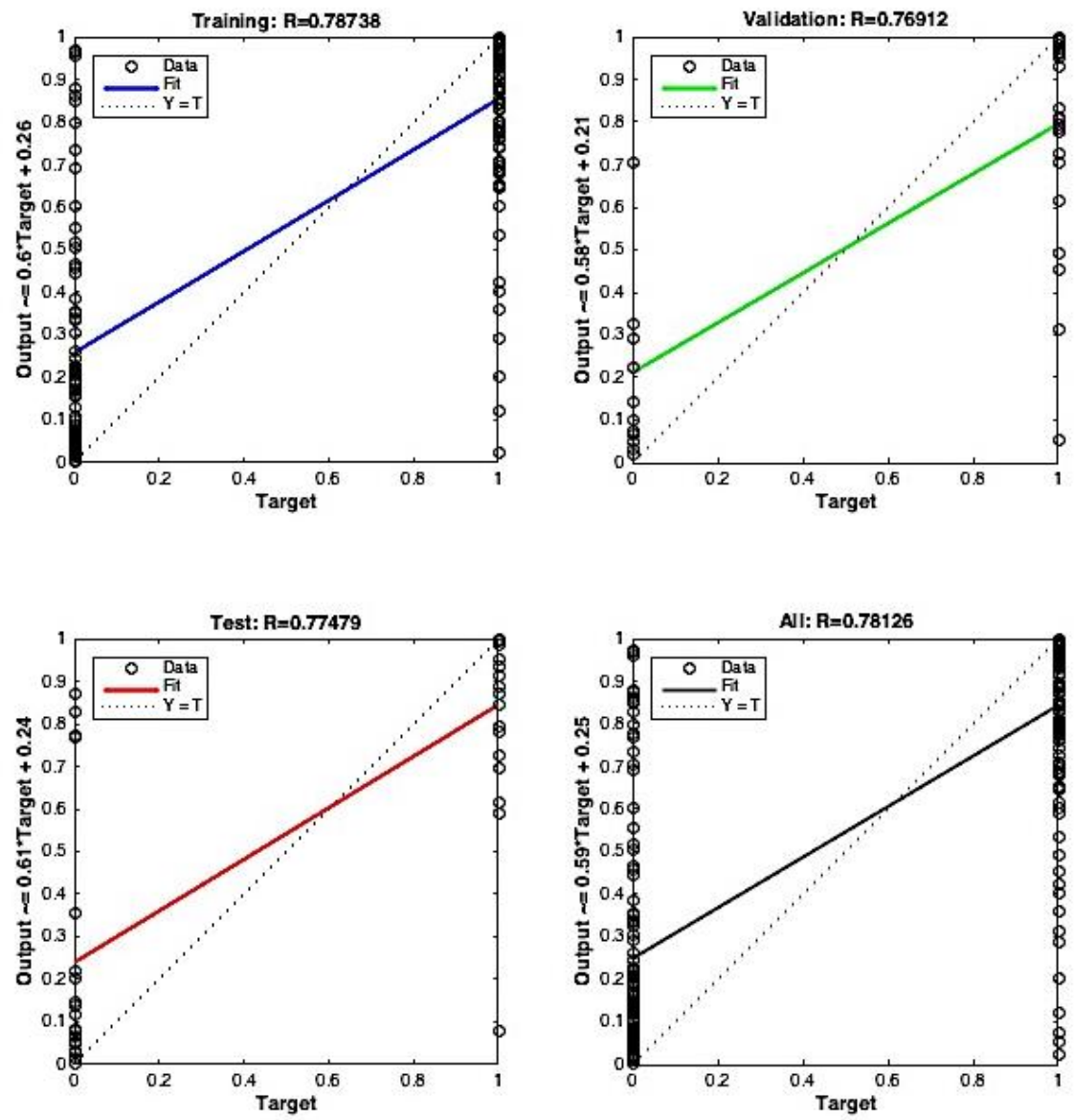

Fig.12. Regression plot trial activation function tansig-purelin (a)Training (b) Validation (c) Testing (d) 
Multiclass confusion matrices for batik image classification are shown in Table 2. True Class (TC) is the number of class members batik image is right on target in the neural network. False Class (FC) is the number of class members batik the wrong classification in classes other batiks. Similarly with the classification results in a class of another batik.

Table 2. Multiclass of Confusion Matrices

\begin{tabular}{|c|c|c|c|c|c|c|c|c|}
\hline \multirow{2}{*}{\multicolumn{2}{|c|}{$\begin{array}{c}\text { TC }=\text { True } \\
\text { Class } \\
\text { FC=False } \\
\text { Class }\end{array}$}} & \multicolumn{7}{|c|}{ OUTPUT CLASS } \\
\hline & & $\mathrm{C} 1$ & $\mathrm{C} 2$ & C3 & $\mathrm{C} 4$ & C5 & C6 & C7 \\
\hline \multirow{7}{*}{ 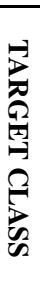 } & $\mathrm{C} 1$ & $\mathrm{TC1}$ & $\mathrm{FC} 1$ & $\mathrm{FC} 1$ & $\mathrm{FC1}$ & $\mathrm{FC} 1$ & FC1 & FC1 \\
\hline & $\mathrm{C} 2$ & $\mathrm{FC} 2$ & $\mathrm{TC} 2$ & $\mathrm{FC} 2$ & $\mathrm{FC} 2$ & $\mathrm{FC} 2$ & $\mathrm{FC} 2$ & $\mathrm{FC} 2$ \\
\hline & C3 & FC3 & $\mathrm{FC} 3$ & TC3 & FC3 & FC3 & FC3 & FC3 \\
\hline & $\mathrm{C} 4$ & FC4 & FC4 & FC4 & $\mathrm{TC4}$ & $\mathrm{FC4}$ & FC4 & FC4 \\
\hline & $\mathrm{C} 5$ & FC5 & FC5 & FC5 & FC5 & TC5 & FC5 & FC5 \\
\hline & C6 & FC6 & FC6 & FC6 & FC6 & FC6 & TC6 & FC6 \\
\hline & C7 & FC7 & FC7 & FC7 & FC7 & FC7 & FC7 & TC7 \\
\hline
\end{tabular}

To calculate the recall, the precision, the accuracy and error rate classification of all classes using (12), (13), (14) and (15).

$$
\begin{gathered}
\text { recall }=T C / \text { outputclass_true } \\
\text { precision }=T C / \text { targetclass_true } \\
\text { accuracy }=\frac{T C 1+T C 2+\cdots+T C 7}{C 1+C 2+\cdots+C 7} \\
\text { errorrate }=100-\text { Accuracy }
\end{gathered}
$$

The train ing we did in the study consisted of training a neural network involving the texture input, shape input and textures-shape input.

We described the number of batik image that can be classified correctly and that can not be classified properly on training using texture features, shape features, and shape-texture features in multiclass confusion matrices that shown in Table 3, Table 4 and Table 5.

Table 3. Confusion matrices of Batik classification training result with texture feature

\begin{tabular}{|c|c|l|l|l|l|l|l|l|}
\hline \multirow{2}{*}{ Batik Classes } & \multicolumn{7}{|c|}{ OUTPUT TEXTURE FEATURE } \\
\cline { 2 - 10 } & C & Gr & G & K & MM & P & SA \\
\hline \multirow{4}{*}{ Ceplok } & 11 & 0 & 2 & 0 & 0 & 0 & 0 \\
\hline Grompol & 0 & 11 & 1 & 0 & 0 & 0 & 0 \\
\hline & Gurda & 0 & 0 & 13 & 0 & 0 & 0 & 1 \\
\hline Kawung & 3 & 0 & 2 & 8 & 0 & 1 & 0 \\
\cline { 2 - 10 } & Mega Mendung & 0 & 0 & 0 & 1 & 13 & 0 & 0 \\
\hline & Parang & 0 & 0 & 0 & 0 & 0 & 14 & 0 \\
\hline Sido Asih & 0 & 0 & 0 & 0 & 0 & 0 & 14 \\
\hline & Total & 14 & 11 & 18 & 9 & 13 & 15 & 15 \\
\hline
\end{tabular}

Table 3 shows the results of the classification training batik texture features. There is some batik image that are not classified correctly. There are two images that are targeted as a class of ceplok but recognizable as a class of Gurda. One image Grompol recognized as a class of Gurda. Misclassification is most present in Kawung class. There are three images kawung recognized as a class of ceplok, two batik images are recognized as a class of Gurda and one kawung image are recognized as a class of

\begin{tabular}{|c|c|c|c|c|c|c|c|c|}
\hline \multirow{2}{*}{\multicolumn{2}{|c|}{ Batik Classes }} & \multicolumn{7}{|c|}{ OUTPUT SHAPE FEATURE } \\
\hline & & $\mathrm{C}$ & Gr & G & $\mathrm{K}$ & $\mathrm{MM}$ & $\mathrm{P}$ & SA \\
\hline \multirow{8}{*}{ 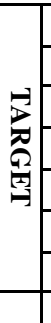 } & Ceplok & 9 & 2 & 1 & 2 & 0 & 0 & 0 \\
\hline & Grompol & 0 & 11 & 1 & 0 & 0 & 0 & 0 \\
\hline & Gurda & 0 & 3 & 11 & 0 & 0 & 0 & 0 \\
\hline & Kawung & 1 & 1 & 1 & 8 & 3 & 0 & 0 \\
\hline & Mega Mendung & 0 & 0 & 0 & 0 & 14 & 0 & 0 \\
\hline & Parang & 0 & 0 & 0 & 0 & 0 & 14 & 0 \\
\hline & Sido Asih & 0 & 0 & 0 & 0 & 0 & 0 & 14 \\
\hline & Total & 10 & 17 & 14 & 10 & 17 & 14 & 14 \\
\hline
\end{tabular}
Parang.

Table 4. Confusion matrices of Batik classification training result with shape feature

For kawung image shape feature also has the greatest misclassification. There are six classified batik image Ceplok class, Grompol class, Gurda class and mega mendung class. When the texture and shape features were used to classify the number of images obtained kawung kawung misclassified reduced to one image at Grompol

\begin{tabular}{|c|c|c|c|c|c|c|c|c|}
\hline \multirow{2}{*}{\multicolumn{2}{|c|}{ Batik Classes }} & \multicolumn{7}{|c|}{$\begin{array}{l}\text { OUTPUT TEXTURE-SHAPE } \\
\text { FEATURE }\end{array}$} \\
\hline & & $\mathrm{C}$ & $\mathrm{Gr}$ & $\mathrm{G}$ & $\mathrm{K}$ & $\mathrm{MM}$ & $P$ & SA \\
\hline \multirow{8}{*}{$\overrightarrow{0}$} & Ceplok & 14 & 0 & 0 & 0 & 0 & 0 & 0 \\
\hline & Grompol & 0 & 13 & 0 & 0 & 0 & 0 & 0 \\
\hline & Gurda & 0 & 1 & 12 & 0 & 1 & 0 & 0 \\
\hline & Kawung & 0 & 0 & 1 & 11 & 2 & 0 & 0 \\
\hline & Mega Mendung & 0 & 0 & 0 & 0 & 14 & 0 & 0 \\
\hline & Parang & 0 & 0 & 0 & 1 & 0 & 13 & 0 \\
\hline & Sido Asih & 0 & 0 & 0 & 0 & 0 & 0 & 14 \\
\hline & Total & 14 & 14 & 13 & 12 & 17 & 13 & 14 \\
\hline
\end{tabular}
class and two image in mega mendung class.

Table 5. Confusion matrices of Batik classification training result with texture-shape feature

Table 6. Confusion matrices of Batik classification testing result with texture feature

\begin{tabular}{|l|l|l|l|l|l|l|l|l|}
\hline \multirow{2}{*}{\multicolumn{2}{|c|}{ Batik Classes }} & \multicolumn{7}{|c|}{ OUTPUT TEXTURE FEATURE } \\
\cline { 2 - 9 } & C & Gr & G & K & MM & P & SA \\
\hline \multirow{4}{*}{} & Ceplok & 4 & 0 & 0 & 0 & 2 & 0 & 0 \\
\cline { 2 - 10 } & Grompol & 0 & 6 & 0 & 0 & 0 & 0 & 0 \\
\cline { 2 - 10 } & Gurda & 0 & 2 & 4 & 0 & 0 & 0 & 0 \\
\cline { 2 - 10 } & Kawung & 0 & 0 & 0 & 6 & 0 & 0 & 0 \\
\cline { 2 - 10 }$\rightarrow$ & Mega Mendung & 0 & 0 & 0 & 1 & 5 & 0 & 0 \\
\cline { 2 - 10 } & Parang & 0 & 0 & 1 & 0 & 0 & 4 & 1 \\
\cline { 2 - 10 } & Sido Asih & 0 & 0 & 0 & 0 & 0 & 0 & 6 \\
\hline & Total & 4 & 8 & 5 & 7 & 7 & 4 & 7 \\
\hline
\end{tabular}

The number of batik image that can be classified correctly and that can not be classified properly on testing using texture features, shape features, and shape-texture 
features in multiclass confusion matrices that shown in Table 6, Table 7, and Table 8 .

Table 7. Confusion matrices of Batik classification testing result with shape feature

\begin{tabular}{|c|c|l|l|l|l|l|l|l|}
\hline \multirow{2}{*}{ Batik Classes } & \multicolumn{7}{|c|}{ OUTPUT SHAPE FEATURE } \\
\cline { 2 - 10 } & C & Gr & G & K & MM & P & SA \\
\hline \multirow{4}{*}{ Ceplok } & 6 & 0 & 0 & 0 & 0 & 0 & 0 \\
\cline { 2 - 10 } & Grompol & 0 & 3 & 3 & 0 & 0 & 0 & 0 \\
\hline Gurda & 0 & 0 & 5 & 0 & 0 & 1 & 0 \\
\hline & Kawung & 2 & 0 & 0 & 3 & 1 & 0 & 0 \\
\cline { 2 - 10 } & Mega Mendung & 0 & 0 & 1 & 0 & 5 & 0 & 0 \\
\hline & Parang & 0 & 0 & 0 & 0 & 0 & 6 & 0 \\
\hline & Sido Asih & 0 & 0 & 0 & 0 & 0 & 0 & 6 \\
\hline & Total & 8 & 3 & 9 & 3 & 6 & 7 & 6 \\
\hline
\end{tabular}

Table 8. Confusion matrices of Batik classification testing result with texture-shape feature

\begin{tabular}{|c|c|c|l|l|l|l|l|l|}
\hline \multirow{2}{*}{ Batik Classes } & \multicolumn{7}{|c|}{ OUTPUT TEXTURE-SHAPE } \\
\cline { 2 - 10 } & C & Gr & G & K & MM & P & SA \\
\hline \multirow{4}{*}{ Ceplok } & 6 & 0 & 0 & 0 & 0 & 0 & 0 \\
\hline Grompol & 0 & 6 & 0 & 0 & 0 & 0 & 0 \\
\hline Gurda & 0 & 0 & 6 & 0 & 0 & 0 & 0 \\
\hline Kawung & 0 & 0 & 0 & 5 & 1 & 0 & 0 \\
\hline Mega Mendung & 0 & 0 & 0 & 1 & 4 & 0 & 1 \\
\hline & Parang & 0 & 0 & 0 & 1 & 0 & 5 & 0 \\
\hline Sido Asih & 0 & 0 & 0 & 0 & 0 & 0 & 6 \\
\hline & Total & 6 & 6 & 6 & 7 & 5 & 5 & 7 \\
\hline
\end{tabular}

Table 9. Recall, Precision, Accuracy and error rate Batik classification training with texture feature and shape feature

\begin{tabular}{|c|c|c|c|c|}
\hline \multirow{2}{*}{ Batik Classes } & \multicolumn{2}{|c|}{ texture feature } & \multicolumn{2}{c|}{ shape feature } \\
\cline { 2 - 5 } & $\begin{array}{c}\text { recall } \\
(\boldsymbol{\%})\end{array}$ & $\begin{array}{c}\text { precision } \\
(\%)\end{array}$ & $\begin{array}{c}\text { recall } \\
(\%)\end{array}$ & $\begin{array}{c}\text { precision } \\
(\%)\end{array}$ \\
\hline Ceplok & 84.62 & 78.57 & 64.29 & 90.00 \\
\hline Grompol & 91.67 & 100.00 & 91.67 & 64.71 \\
\hline Gurda & 92.86 & 72.22 & 78.57 & 78.57 \\
\hline Kawung & 57.14 & 88.89 & 57.14 & 80.00 \\
\hline Mega Mendung & 92.86 & 100.00 & 100.00 & 82.35 \\
\hline Parang & 100.00 & 93.33 & 100.00 & 100.00 \\
\hline Sido Asih & 100.00 & 93.33 & 100.00 & 100.00 \\
\hline accuracy(\%) & \multicolumn{2}{|c|}{$\mathbf{8 5 . 7 1}$} & \multicolumn{2}{|c|}{$\mathbf{8 2 . 6 5}$} \\
\hline error rate (\%) & \multicolumn{2}{|c|}{$\mathbf{1 4 . 2 9}$} & \multicolumn{2}{|c|}{$\mathbf{1 7 . 3 5}$} \\
\hline
\end{tabular}

Table 10. Recall, Precision, Accuracy and error rate Batik classification testing result with texture-shape feature

\begin{tabular}{|c|c|c|}
\hline \multirow{2}{*}{ Batik Classe } & \multicolumn{2}{|c|}{ texture-shape feature } \\
\cline { 2 - 3 } & recall (\%) & precision (\%) \\
\hline Ceplok & 100.00 & 100.00 \\
\hline Grompol & 100.00 & 92.86 \\
\hline Gurda & 85.71 & 92.31 \\
\hline Kawung & 78.57 & 91.67 \\
\hline Mega Mendung & 100.00 & 82.35 \\
\hline Parang & 92.86 & 100.00 \\
\hline Sido Asih & 100.00 & 100.00 \\
\hline accuracy (\%) & \multicolumn{2}{|c|}{$\mathbf{9 2 . 8 6}$} \\
\hline error rate (\%) & $\mathbf{2 . 1 4}$ \\
\hline
\end{tabular}

The results of the training and testing of the entire training data and test data in this study can be seen in Table 9, Table 10, Table 11 and Table 12.

Table 11. Recall, Precision, Accuracy and error rate Batik classification testing with texture feature and shape feature

\begin{tabular}{|c|c|c|c|c|}
\hline \multirow{2}{*}{ Batik Classes } & \multicolumn{2}{|c|}{ texture feature } & \multicolumn{2}{c|}{ shape feature } \\
\cline { 2 - 5 } & $\begin{array}{c}\text { recall } \\
(\mathbf{\%})\end{array}$ & $\begin{array}{c}\text { precision } \\
(\mathbf{\%})\end{array}$ & $\begin{array}{c}\text { recall } \\
(\mathbf{\%})\end{array}$ & $\begin{array}{c}\text { precision } \\
(\%)\end{array}$ \\
\hline Ceplok & 66.67 & 100.00 & 100.00 & 75.00 \\
\hline Grompol & 100.00 & 75.00 & 50.00 & 100.00 \\
\hline Gurda & 66.67 & 80.00 & 83.33 & 55.56 \\
\hline Kawung & 100.00 & 85.71 & 50.00 & 100.00 \\
\hline Mega Mendung & 83.33 & 71.43 & 83.33 & 83.33 \\
\hline Parang & 66.67 & 100.00 & 100.00 & 85.71 \\
\hline Sido Asih & 100.00 & 85.71 & 100.00 & 100.00 \\
\hline accuracy(\%) & \multicolumn{2}{|c|}{$\mathbf{8 3 . 3 3}$} & \multicolumn{2}{c|}{$\mathbf{8 0 . 9 5}$} \\
\hline error rate (\%) & \multicolumn{2}{|c|}{$\mathbf{1 6 . 6 7}$} & \multicolumn{2}{c|}{$\mathbf{1 7 . 0 5}$} \\
\hline
\end{tabular}

Table 12. Recall, Precision, Accuracy and error rate Batik classification testing result with texture-shape feature

\begin{tabular}{|c|c|c|}
\hline \multirow{2}{*}{ Batik Classes } & texture-shape feature \\
\cline { 2 - 3 } & recall (\%) & precision (\%) \\
\hline Ceplok & 100.00 & 100.00 \\
\hline Grompol & 100.00 & 100.00 \\
\hline Gurda & 100.00 & 100.00 \\
\hline Kawung & 83.33 & 71.43 \\
\hline Mega Mendung & 66.67 & 80.00 \\
\hline Parang & 83.33 & 100.00 \\
\hline Sido Asih & 100.00 & 85.71 \\
\hline accuracy (\%) & \multicolumn{2}{|c|}{$\mathbf{9 0 . 4 8}$} \\
\hline error rate (\%) & \multicolumn{2}{|c|}{} \\
\hline
\end{tabular}

The training that we do using texture feature generates training data overall accuracy of $85.71 \%$ for training data and $83.33 \%$ for test data. Output class that has the highest accuracy is Parang and sido asih class at $100 \%$. Batik classes that has the lowest accuracy is batik image kawung class.

The training that we do using shape feature generates training data overall accuracy of $83.33 \%$ and $80.95 \%$ for test data. Classification by shape feature batik image has an accuracy rate that is lower than the classification accuracy using texture features. This is caused by the shape feature batik image has a size edge of the line of diverse and different sizes. There are the same size but a different class. The results of the training and testing by combining the shape-texture training data and test data shape-texture produces an accuracy of $92.86 \%$ and accuracy of test data by $90.48 \%$.

\section{CONCLUSION}

Batik Indonesia has texture and shape of typical ornaments that can be used to classify each class of batik. The accuracy obtained for classifying the image of batik texture features higher compared to using shape features ornaments. It is due to the form of ornaments batik image has a size and shape that vary widely in one class. 
Training with shape feature and testing with shape feature have the lowest accuracy of $82.65 \%$ (training) and $80.95 \%$ (testing). It is caused by the size of different batik some large and some small in the same class. By combining the features of texture and shape features can increase the accuracy values become $90.48 \%$.

\section{REFERENCES}

[1] A. Kitipong, W. Rueangsirasak, and R. Chaisricharoen, "Classification System for Traditional Textile: Case Study of the Batik," in 13th International Symposium on Communications and Information Technologies (ISCIT) Classification, 2013, pp.767-771.

[2] Kar Seng Loke, Pattern Recognition: An Approach to Textile Recognition. Shan ghai, China: InTech China, 2009.

[3] Sugiyem, "Makna Filosofi Batik," WUNY Lemb. Pengabdi. Kpd. Masy. Univ. Negeri Yogyakarta, vol. X, pp. 1-10, 2008.

[4] V. Moertini, "Towards Classifying Classical Batik Images," Bandung, 2005.

[5] I. Nurhaida, A. Noviyanto, R. Manurung, and A. M. Arymurthy, "Automatic Indonesian's Batik Pattern Recognition Using SIFT Approach," Procedia - Procedia Comput. Sci., vol. 59, no. Iccsci, pp. 567-576, 2015.

[6] N. Suciati, W. A. Pratomo, and D. Purwitasari, "Batik Motif Classification using Color-Texture-Based Feature Extraction and B ackpropagation Neural Network," in IIAI 3rd International Conference on Advanced Applied Informatics, 2014, pp. 517-521.

[7] Imanudin, "Batik Identification Based On Batik Pattern And Characteristics Using Fabric Pattern Feature Extraction," 2010.

[8] V. S. Moertini and B. Sitohang, "Algorithms of Clustering and Classifying Batik Images Based on Color, Contrast and Motif," in PROC. ITB Eng. Science, 2005, vol. 37, no. 2, pp. $141-160$.

[9] A. E. Minarno, Y. Munarko, A. Kurniawardhani, F. Bimantoro, and N. Suciati, "Texture Feature Extraction Using Co-Occurrence Matrices of Sub-Band Image For Batik Image Classification," in 2nd International Conference on Information and Communication Technology (ICoICT) Texture, 2014, pp. 249-254.

[10] A. D. Nugrowati, A. R. Barakbah, N. Ramadijanti, and Y. Setiowati, "Batik Image Search System with Extracted Combination of Color and Shape Features," in International Conference on Imaging and Printing Technologies, 2014.

[11] E. K. O. Aribowo and Murinto, "Image Segmentation Using Hidden Markov Tree Methods in Recognizing Motif of Batik," J. Theor. Appl. Inf. Technol., vol. 85, no. 1, pp. 27-33, 2016.

[12] C. S. K. Aditya, M. Hani'ah, R. R. Bintana, and N. Suciati, "Batik Classification using Neural Network with Gray Level Co-occurence Matrix and Statistical Color Feature Extraction," in 2015 International Conference on International, Communication Technology and System (ICTS), 2015, pp. 163-168.

[13] C. N. Rao, S. S. Sastry, K. Mallika, H. S. Tiong, and K. B. Mahalakshmi, "Co-Occurrence Matrix and Its Statistical Features as an Approach for Identification of Phase Transitions of Mesogens," Int. J. Innov. Res. Sci. Eng. Technol., vol. 2, no. 9, pp. 4531-4538, 2013.

[14] R. Azhar, D. Tuwohingide, D. Kamudi, Sarimuddin, and
N. Suciati, "Batik Image Classification Using SIFT Feature Extraction, Bag of Features and Support Vector Machine," Procedia - Procedia Comput. Sci., vol. 72, pp. 24-30, 2015.

[15] I. Setyawan, I. K. Timotius, and M. Kalvin, "Automatic Batik Motifs Classification using Various Combinations of SIFT Features Moments and k -Nearest Neighbor," in 7th International Conference on Information Technology and Electrical Engineering (ICITEE), Chiang Mai, Thailand, 2015, vol. 3, pp. 269-274.

[16] R. C. Gonzalez and R. E. Woods, Digital Image Processing, Third. New Jersey: Pearson Prentice Hall, 2008.

[17] F. Albregtsen, "Statistical Texture Measures Computed from Gray Level Coocurrence Matrices," Oslo, 2008.

[18] D. Gadkari, "Image Quality Analysis Using GLCM," University of Central Florida Orlando, Florida, 2004.

[19] R. Haralick, K. Shanmugan, and I. Dinstein, "Textural features for image classification," IEEE Trans. Syst. Man Cybern., vol. 3, pp.610-621, 1973.

[20] Nobuyuki Otsu, "A Threshold Selection Method from Gray-Level Histigram," IEEE Trans. Syst. Man Cybern., vol. 20, no. 1, pp. 62-66, 1979.

[21] S. Bhuvaneswari and J. Sabarathinam, "Defect Analysis Using Artificial Neural Network," Int. J. Intell. Syst. Appl., vol. 5, no. 5, pp. 33-38, 2013.

[22] L. Fausett, Fundamental of Neural Network. New Jersey: Prentice Hall, 1993.

[23] M. T. Habib and M. Rokonuzzaman, “An Empirical Method for Optimization of Counterpropagation Neural Network Classifier Design for Fabric Defect Inspection," Int. J. Intell. Syst. Appl., vol. 6, no. 9, pp. 30-39, 2014.

\section{Authors' Profiles}

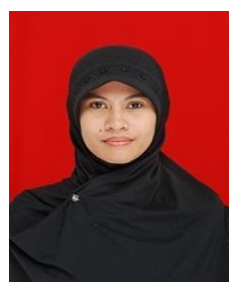

Anita Ahmad Kasim is a lecturer and researcher at the Universitas Tadulako, Palu since 2005. Received the master's degree in computer science from Universitas Gadjah Mada, Indonesia in 2010. Her research interest in fuzzy logic, artificial intelligent and pattern recognition. Now, she is a doctoral student in Department of Computer Science and Electronics, Faculty of Mathematics and Natural Sciences, Universitas Gadjah Mada.

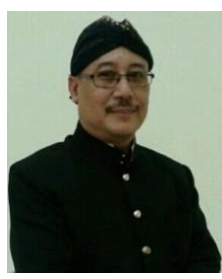

Retantyo Wardoyo is a lecturer and a researcher at Department of Computer Science and Electronics, Faculty of Mathematics and Natural Sciences, Universitas Gadjah Mada. He obtained his bachelor degree from Mathematics in Universitas Gadjah Mada, Indonesia (1982) $\mathrm{He}$ obtained his master degree from Computer Science in University of Manchester, UK (1990) and his doctoral degree from Computation in University of Manchester Institute of Sciences and Technology, UK (1996). His research interests include Intelligent Systems, Reasoning Systems, Expert Systems, Fuzzy Systems, Vision Systems, Group DSS \& Clinical DSS, Medical Computing \& Computational Intelligence. 


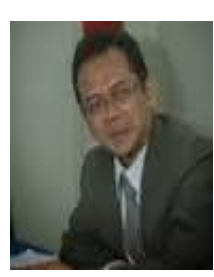

Agus Harjoko is a lecturer and a researcher at Department of Computer Science and Electronics, Faculty of Mathematics and Natural Sciences, Universitas Gadjah Mada. $\mathrm{He}$ is also a member of the Indonesian Physics Society and the Indonesian Mathematical Society. He received the B.S. degree in Electronics and Instrumentation from Universitas Gadjah Mada, Yogyakarta, Indonesia and the M.Sc and Ph.D Degree in Computer Science both from University of New Brunswick, Canada, in 1986, 1990 and 1996. His research interests include multimedia processing (image, audio, video processing), computer vision, and medical instrumentation.

How to cite this paper: Anita Ahmad Kasim, Retantyo Wardoyo, Agus Harjoko,"Batik Classification with Artificial Neural Network Based on Texture-Shape Feature of Main Ornament", International Journal of Intelligent Systems and Applications(IJISA), Vol.9, No.6, pp.55-65, 2017. DOI: 10.5815/ijisa.2017.06.06 